Journal of the Electrochemical Society, 1998, Volume 145, Issue 7, Pages 2295-2306.

ISSN: (Print 0013-4651) (Online 1945-7111)

DOI: $10.1149 / 1.1838634$

http://www.electrochem.org/

http://scitation.aip.org/JES

http://scitation.aip.org/getpdf/servlet/GetPDFServlet?filetype=pdf\&id=JESOAN000145000007002295000001\&idty pe $=$ cvips \&prog $=$ normal

(C) The Electrochemical Society, Inc. 1998. All rights reserved. Except as provided under U.S. copyright law, this work may not be reproduced, resold, distributed, or modified without the express permission of The Electrochemical Society (ECS). The archival version of this work was published in Journal of the Electrochemical Society, 1998, Volume 145, Issue 7, Pages 2295-2306.

\title{
Corrosion Study of AA2024-T3 by Scanning Kelvin Probe Force Microscopy and In Situ Atomic Force Microscopy Scratching
}

\author{
P. Schmutz and G. S. Frankel \\ Fontana Corrosion Center, Department of Materials Science and Engineering, The Ohio State University
}

\begin{abstract}
The localized corrosion of AA2024-T3, and the behavior of intermetallic particles in particular, were studied using different capabilities of the atomic force microscope (AFM). The role of intermetallic particles in determining the locations and rates of localized corrosion was determined using scanning Kelvin probe force microscopy in air after exposure to chloride solutions. Al-Cu-Mg particles, which have a noble Volta potential in air because of an altered surface film, are actively dissolved in chloride solution after a certain induction time. Al-Cu$(\mathrm{Fe}, \mathrm{Mn})$ particles are heterogeneous in nature and exhibit nonuniform dissolution in chloride solution as well as trenching of the matrix around the particles. Light scratching of the surface by rastering with the AFM tip in contact mode in chloride solution results in accelerated dissolution of both pure Al and alloy 2024-T3. The abrasion associated with contact AFM in situ resulted in the immediate dissolution of the Al-Cu-Mg particles because of a destabilization of the surface film.
\end{abstract}

\section{Introduction}

Because of the susceptibility of alloy AA2024 to localized corrosion and its importance in aerospace applications, its corrosion behavior has been studied in some detail. Electrochemical approaches, such as potentiodynamic polarization ${ }^{1}$ and impedance spectroscopy characterization $^{2-4}$ have been used in recent studies. Optical microscopy and scanning electron microscopy (SEM) have also been used to investigate the corroded surface. ${ }^{1}$ The role of intermetallic particles in the alloy was described based on the difference in corrosion potential measured for bulk precipitates and pure metals. ${ }^{5}$ A detailed description of the corrosion of $\mathrm{Al}_{2} \mathrm{CuMg}$ particles in AA2024-T3 has been presented by Buchheit et al. ${ }^{6}$ Severe dealloying of these particles, followed by removal of copper clusters, was postulated as an explanation for the distribution of copper across the sample surface after exposure to sodium chloride solution. However, details of the processes involved in this mechanism are not completely understood.

Considerable insight into the mechanism has been gained with these approaches. However, electrochemical methods lack micrometer-scale lateral resolution, which is critical for understanding the role of intermetallic particles in localized corrosion, and microscopic methods lack chemical identification and in situ capability. Furthermore, initiation and the early stages of localized corrosion are difficult to study by any technique.

Atomic force microscopy (AFM) is useful for the study of localized corrosion of passive 
metals because surfaces that need not be conductive can be imaged in situ with high lateral resolution. The role of intermetallic particles in the corrosion behavior of $\mathrm{Al}$ alloys has been followed in solution ${ }^{7}$ or after exposure. ${ }^{8}$ Rynders et al. used Auger electron spectroscopy (AES) to identify the composition of particular $\mathrm{Al}_{3} \mathrm{Fe}$ intermetallic particles in AA6061-T6. ${ }^{7}$ Trenches in the surrounding matrix were observed to form in $0.6 \mathrm{M} \mathrm{NaCl}$ using contact mode in situ AFM. Alloy AA2024 was studied ex situ following exposure to $1 \mathrm{M} \mathrm{NaCl}+\mathrm{H}_{2} \mathrm{O}_{2}$, and trenches surrounding particles were also observed. ${ }^{8}$ SEM and X-ray energy dispersive spectroscopy (EDS) were used after the AFM observation to determine the elemental composition of the precipitates. Kowal et al. used contact mode in situ AFM to monitor surface topography of AA2024-T3 in HC1 solutions. ${ }^{9}$ Attack around particles was monitored with time, but the original shape and composition of the particles were not determined. In all of these studies, trenching around particles was attributed to the nobility of the particle relative to the matrix. Grain boundary corrosion was also observed for more aggressive $\mathrm{HC1}$ solutions or for under-aged alloys. ${ }^{8}$ Small pits also formed at apparently random locations on the surface.

In the present work, two different approaches to the study of localized corrosion of $\mathrm{Al}$ alloys with AFM are utilized: in situ AFM scratching and Volta potential mapping. Studies of repassivation of freshly bared surfaces generated by various means, including scratching, ${ }^{10}$ breaking, ${ }^{11}$ or guillotining ${ }^{12}$ the electrode, have provided considerable insight into passivity. Pressure applied by an AFM tip on the surface of a sample during in situ contact mode rastering is a form of scratching on the microscale. Guay et al. showed that the dissolution rate of pure aluminum thin films is locally enhanced during controlled AFM rastering in dilute chloride solutions. ${ }^{13,14}$ The loss of material was followed by determining the average roughness as a function of time. A relation between the applied force and the decrease of roughness was observed. ${ }^{14}$ In the present study, AFM scratching is used to stimulate local depassivation events near different intermetallic particles.

In corrosion studies the AFM has primarily been used for following surface topography, although recent reports demonstrate other novel applications of the AFM. In an attempt to investigate the earliest stages of localized corrosion, a conductive AFM tip was used in situ to measure local current distribution. ${ }^{15}$ Current mapping in the picoampere range was possible, which allowed the detection of current instabilities at locations prior to the initiation of localized corrosion.

The AFM can also be used to map the potential distribution of the surface in air. A recent report by the authors describes the usefulness of scanning Kelvin probe force microscopy for characterizing AA 2024-T3. ${ }^{16}$ Even though the measurement was performed in air, the Volta potential determined by Kelvin probe force microscopy was found to be a good measure of practical nobility; a strong correlation was found between the measured potential and the corrosion potential measured in solution.

Potential measurements have been performed in solution by force microscopy using a different approach. A nonconducting tip will be either attracted to or repulsed from an electrode surface in solution depending on the surface charges. Hillier and Bard ${ }^{17}$ measured the force vs. the distance curve between gold and a silica tip in different solutions, and a theoretical treatment of the electrostatic interaction in electrolyte solution was given by Butt. ${ }^{18}$ By applying a potential to the sample, it is possible to determine the potential of zero charge, which is at the transition between attractive and repulsive behavior The type and concentration of the ionic species in solution also have an influence by altering the diffuse double layer. Imaging of a surface in this electrical double layer mode has been performed by Senden et al. ${ }^{19}$ 


\section{Experimental}

A commercial atomic force microscope (Nanoscope IIIa, Digital Instruments) was used in this study. The procedure for mapping the Volta potential in air has been previously described. ${ }^{16}$ In this study, samples of AA2024-T3 (nominal composition 4.9-3.8\% Cu, 1.8-1.2\% $\mathrm{Mg}, 0.9-0.3 \% \mathrm{Mn}, 0.5 \% \mathrm{Fe}$ and $\mathrm{Si}, 0.25 \% \mathrm{Zn}, 0.1 \% \mathrm{Cr}, 0.05 \mathrm{Ti}$, balance $\mathrm{Al}$ ) were prepared by polishing in a nonaqueous slurry and cleaning in isopropyl alcohol (IPA) as also described in the previous paper. Areas of interest were identified using the AFM in air, and the topographic (using tapping mode and a CoCr-coated silicon tip) and potential distribution maps were recorded. Compositional analysis of the intermetallic particles in the same areas was then performed with EDS in a Philips Electronics model XL-30 SEM equipped with a field emission gun, an EDAX Corporation model DX-4 EDS system, and a superultrathin window for higher sensitivity. An accelerating voltage of $12 \mathrm{kV}$ was used for both secondary electron imaging and EDS analysis.

Some samples were then covered with a droplet of $\mathrm{NaCl}$ solution that was formulated from reagent grade salt and Millipore deionized water. A droplet was used to imitate the exposure experienced in the AFM fluid cell, which is small. These samples were periodically rinsed with water, air dried, and then re-examined in the AFM in air for topographic and Volta potential mapping.

Other samples were examined in situ in chloride solution with the Digital Instruments fluid cell using contact mode AFM and a silicon tip. The tip was rastered in situ across some samples for varying periods of time. The samples were then removed from solution, rinsed, dried, and re-examined in air for topography and Volta potential. The effect of tip pressure during in situ contact rastering was determined on a sample of commercially pure AA1100 in 0.5 $\mathrm{M} \mathrm{NaCl}$. Varying pressures were applied by changing the set point voltage on the photodetecter sensor that monitors the cantilever deflection. A $15 \times 15 \mu \mathrm{m}$ region was rastered for $30 \mathrm{~min}$ at a certain set point voltage in the range of $0.2-5 \mathrm{~V}$. The set point voltage was then reduced to $0.2 \mathrm{~V}$, and the scanned region was increased to $30 \times 30 \mu \mathrm{m}$. The rate of recession of the rastered area relative to the neighboring unrastered region was then determined.

\section{Results and Discussion}

Immersion tests in $\mathrm{NaCl}$ solution.-The first series of experiments utilized ex situ AFM topographic and Volta potential mapping to examine the corrosion that occurred at different intermetallic particles in AA2024-T3 during immersion in $\mathrm{NaCl}$ solution. The topography and Volta potential maps of the selected region in air before immersion are given in Fig. 1. The topographic map indicates that several pits are already present on the surface, one associated with particle 5 and one with particle A. These pits formed during the initial surface preparation, despite attempts to minimize exposure to water during that time. Figure 2 shows the SEM image of the same region. EDS analysis indicated that particles 1-5 are $\mathrm{Al}-\mathrm{Cu}-(\mathrm{Fe}, \mathrm{Mn})$, and particles $\mathrm{A}$ and $\mathrm{B}$ are $\mathrm{Al}-\mathrm{Cu}-\mathrm{Mg}$. Particles 4 and 5 exhibited lower potentials than particles 1-3 so there are apparently different types of $\mathrm{Al}-\mathrm{Cu}-(\mathrm{Fe}, \mathrm{Mn})$ particles with different Volta potentials. Note that there are bright spots with high potential visible on some analyzed particles in the Volta potential

map of Fig. 1. As mentioned previously, ${ }^{16}$ the electron-beam used for EDS analysis induced a Volta potential increase of approximately $+100 \mathrm{mV}$ at the analysis spot. This is most probably 
the result of carbon contamination in the SEM. EDS analysis was performed for $15 \mathrm{~s}$ on particles A and 4, and a bright spot was generated. However, reducing the EDS analysis time to $5 \mathrm{~s}$ on particles B and 5 resulted in a potential image with no detectable contamination spot.

The sample was then immersed in $0.1 \mathrm{M} \mathrm{NaCl}$ solution for varying periods of time and re-examined in the AFM. Figure 3 shows the topography and Volta potential in air after 5 min of immersion in $0.1 \mathrm{M} \mathrm{NaCl}$. The topographic map indicates that the pit associated with particle 5 grew in size during the exposure. It also changed shape, as the center of the pit is now partially covered. The Volta potential image also reveals different interesting features. First, the particle edges are much less defined then before immersion. The contrast at the particle edges has decreased as a result of the exposure to the corrosive solution. This phenomenon is related to the observation made previously that the Volta potential contrast at intermetallic particles improves after renewal of the surface by sputter etching to the extent where heterogeneities in the Fe-Mncontaining particles became clearly evident. ${ }^{16}$ The implication in that work was that aging and thickening of the oxide during prolonged exposure to air resulted in homogenization of the particle Volta potential and loss of contrast. Figure 3 indicates that a more severe loss of contrast across the whole area results after only $5 \mathrm{~min}$ of exposure to $0.1 \mathrm{M} \mathrm{NaCl}$. The homogenization of the Volta potential may result directly from a thickening of the oxide film corrosion product. Homogenization of the oxide chemistry, however, may also play a role. Regardless, the exposure to chloride solution certainly results in a masking of the considerable heterogeneities existing in the underlying metal.

The Fe-Mn containing particles 1-3 show a decrease of Volta potential of around $50 \mathrm{mV}$ after the 5 min of exposure. Interestingly, the holes now have the highest Volta potential on the map, with values around $-350 \mathrm{mV}$. There are some corrosion products around the holes visible on the topographic image. One explanation for the noble potentials in the pits is that $\mathrm{Cu}$ is enriched as a result of preferential dissolution of the other elements. The $\mathrm{Mg}$-containing particle $\mathrm{A}$ had a pit associated with it prior to the exposure, and this pit evolves in a similar fashion to the larger pit associated with the $\mathrm{Al}-\mathrm{Cu}-(\mathrm{Fe}, \mathrm{Mn})$ particle. The particle itself is not corroded, but the pit next to it is growing. The Volta potential of the Mg-containing particle B is decreased after the $5 \mathrm{~min}$ exposure, but the topographic map indicates that no corrosion has occurred.

The sample was then returned to the $0.1 \mathrm{M} \mathrm{NaCl}$ solution. After a total of $30 \mathrm{~min}$ of exposure the holes near particles $\mathrm{A}$ and 5 have increased in size, Fig. 4. The Volta potential contrast has further degraded as the potential of the intermetallic particles has further decreased and the edges are much less defined. A typical value of the Volta potential for the large particles $1-3$ is around -600 to $-550 \mathrm{mV}$ vs. the Ni reference (150-200 $\mathrm{mV}$ more noble than the matrix). After $30 \mathrm{~min}$, the potential of the $\mathrm{Mg}$-containing particle $\mathrm{B}$ is almost identical to that of the matrix, but the topographic map indicates that there is still no evidence of corrosion at or near that particle. 


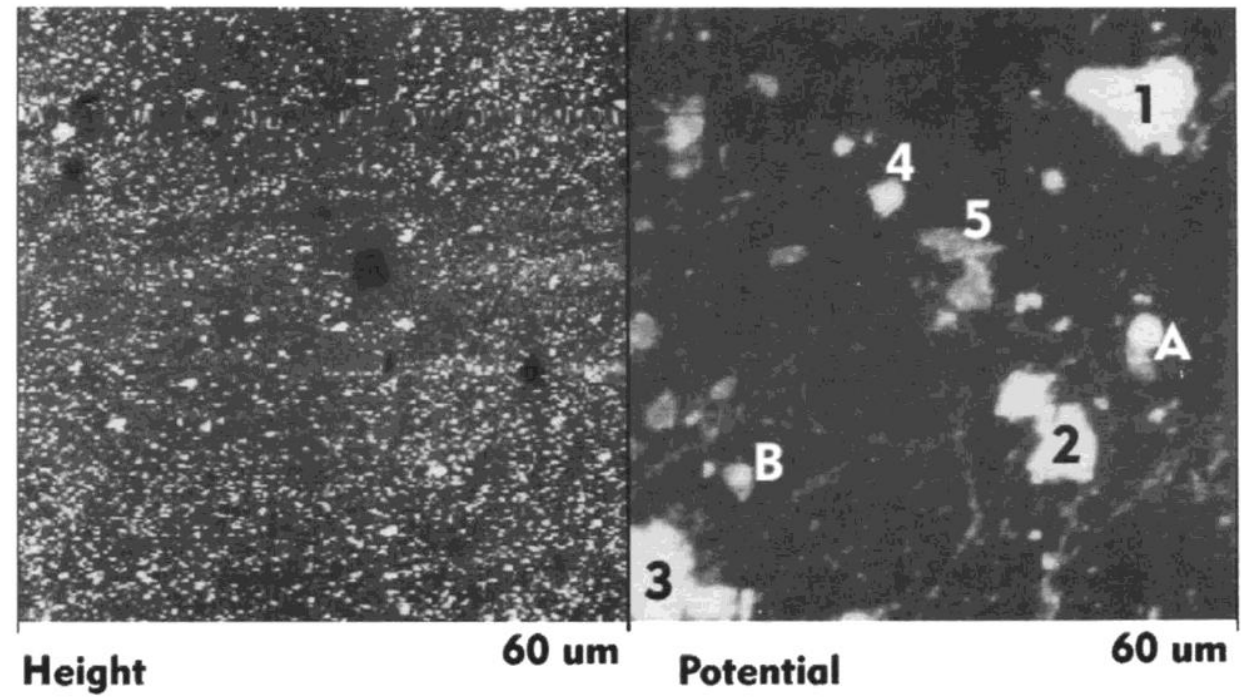

\section{$Z$ range: $300 \mathrm{~nm}$}

$\mathrm{Z}$ range: $1.5 \mathrm{~V}$

Fig. 1. Topography and Volta potential of an AA2024-T3 sample before treatment. Particles 1-5 are AI- $\mathrm{Cu}(\mathrm{Fe}, \mathrm{Mn})$ intermetallics and particles $\mathrm{A}$ and $\mathrm{B}$ are the $\mathrm{Al}-\mathrm{Cu}-\mathrm{Mg}$ intermetallics.

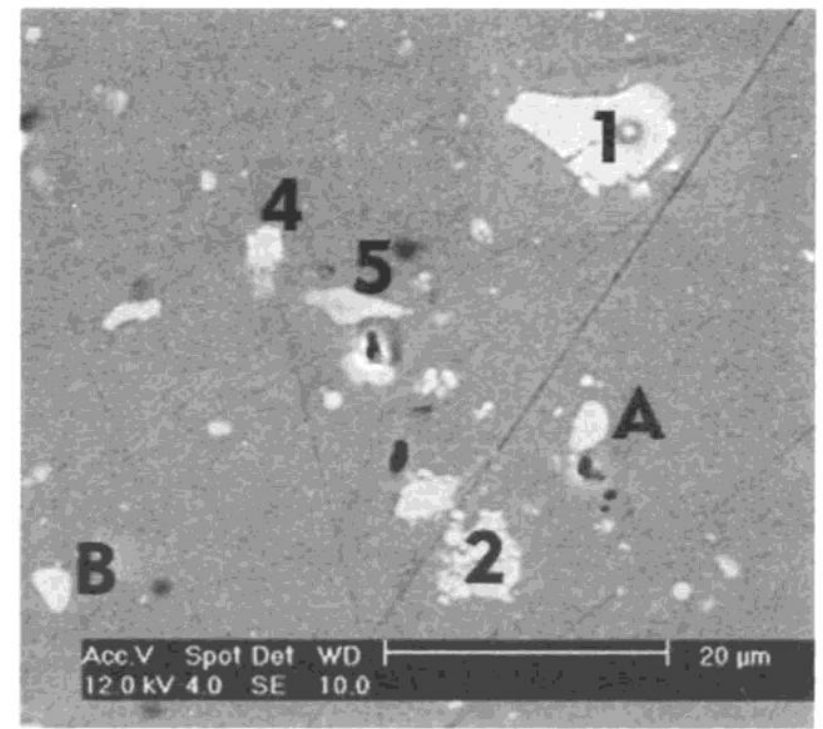

Fig. 2. SEM image of the same area as Fig. 1. Particles 1, 2, 4, and 5 are the $\mathrm{AI}-\mathrm{Cu}-(\mathrm{Fe}, \mathrm{Mn})$ intermetallic particles. (Note that particle 3 from Fig. 1 is not in this field of view.) A and B are Al-Cu-Mg intermetallics.

After 120 min of total exposure time, the contrast has degraded to the extent that there is almost no variation in Volta potential across the whole region, Fig. 5. Interestingly, the $\mathrm{Mg}-$ containing particle B is now completely dissolved. For a considerable period of time, this particle had a noble potential that seemed to protect it from corrosion. After this induction period, however, this potential difference disappeared and the particle dissolved. The induction time could be related to the presence of a surface film with very low dissolution rate that has to be removed before dissolution can occur. As described previously, the potential of the $\mathrm{Mg}$ - 
containing S-phase particles is expected to be active to the matrix in a chloride solution. ${ }^{5}$ The noble Volta potential measured in air was attributed to the presence of an altered surface layer. ${ }^{16}$ When the protection associated with this surface layer is removed, the particle corrodes very quickly. The influence of scratching the surface with the AFM on the stability of this oxide will be addressed below. Mazurkiewicz ${ }^{20}$ reported passivation of $\mathrm{Al}_{8} \mathrm{Mg}_{5}$ above a $\mathrm{pH}$ of 4 . The protective role of $\mathrm{Mg}$ hydroxide is increased with increasing $\mathrm{pH}$.

The Volta potential profile across the Al-Cu-(Fe, Mn) particle 1 in Fig. 1 for the different exposure times in $0.1 \mathrm{M} \mathrm{NaCl}$ is shown in Fig. 6. The potential difference between the particle and the aluminum matrix is largest for the untreated sample and decreases with increasing exposure time. The aluminum matrix becomes more noble and the intermetallic particle becomes less noble with time. As mentioned before, a thickening of the aluminum oxide could explain the increase of measured potential of the matrix. This explanation is consistent with the decrease of potential in a scratched area described in a previous paper. ${ }^{16}$ The decrease in potential of the intermetallic particle may be related to the deposition of corrosion products on the particle. It is shown below that corrosion products typically exhibit a more active Volta potential in air. However, no evidence of dissolution of the particle that could modify the surface chemistry was visible. After $120 \mathrm{~min}$, the contrast almost disappeared as the potential of the whole surface reached a value between the original potentials of the matrix and particles.

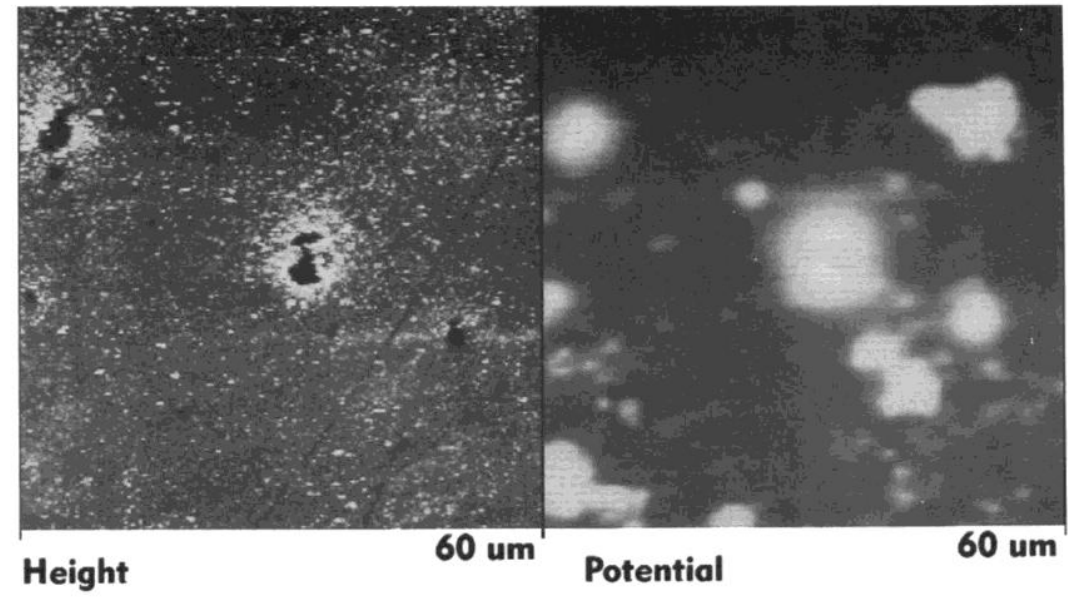

$Z$ range: $300 \mathrm{~nm}$

$\mathrm{Z}$ range: $1.5 \mathrm{~V}$

Fig. 3. Topography and Volta potential of the same area as Fig. 1 after 5 min in $0.1 \mathrm{M} \mathrm{NaCl}$.

Another interesting corrosion phenomenon is shown in Fig. 7-9. In Fig. 7, which was taken before exposure, particle 1 is a Mn-Fe-containing intermetallic. Exposure of this sample to $0.1 \mathrm{M} \mathrm{NaCl}$ for 30 min results in the formation of holes at both ends of the particle, Fig. 8. An enlargement of the area that contains particle 1 seems to indicate that the middle part of the particle remains intact, while part of it dissolved away, Fig. 9. Prior to the exposure there was no indication in the topography or Volta potential maps to suggest that the particle was not homogeneous. Earlier work showed, however, that heterogeneities of Fe-Mn-containing particles could be seen in the Volta potential map after sputter etching, or viewing the backscattered electron image in a SEM. ${ }^{16}$ The fact that parts of Fe-Mn particles are more reactive than other parts, and will dissolve preferentially is supportive of this view. It is interesting that the entire 
particle was noble to the matrix before exposure. Parts of the particle dissolved despite this nobility. This type of behavior was observed in several different samples.

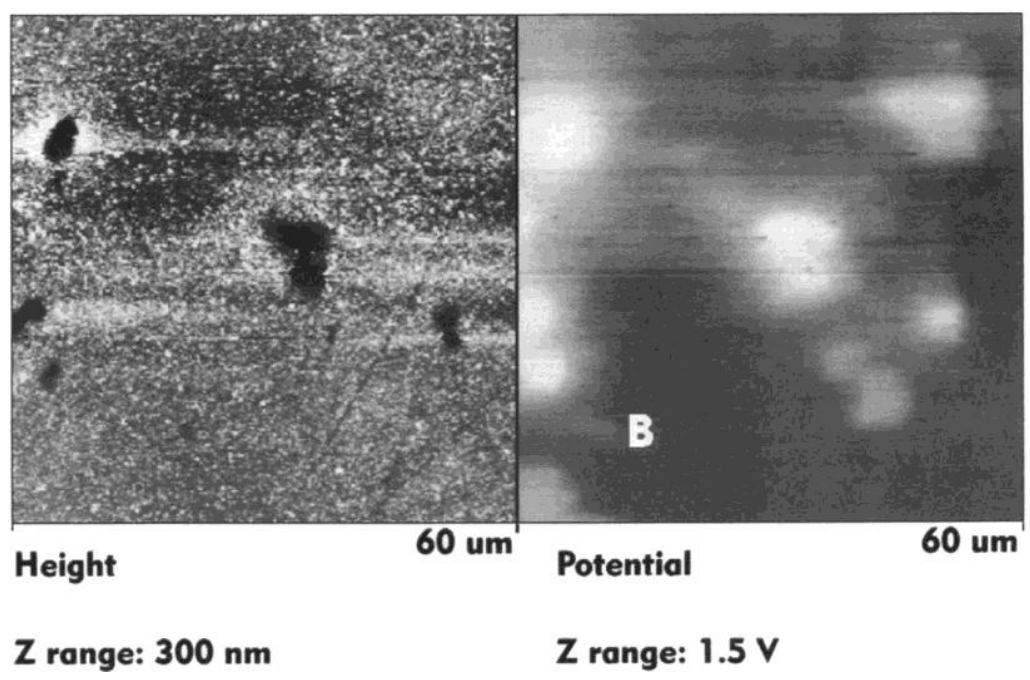

Fig. 4. Topography and Volta potential of the same area as Fig. 1 after 30 min of total exposure in $0.1 \mathrm{M} \mathrm{NaCl}$.

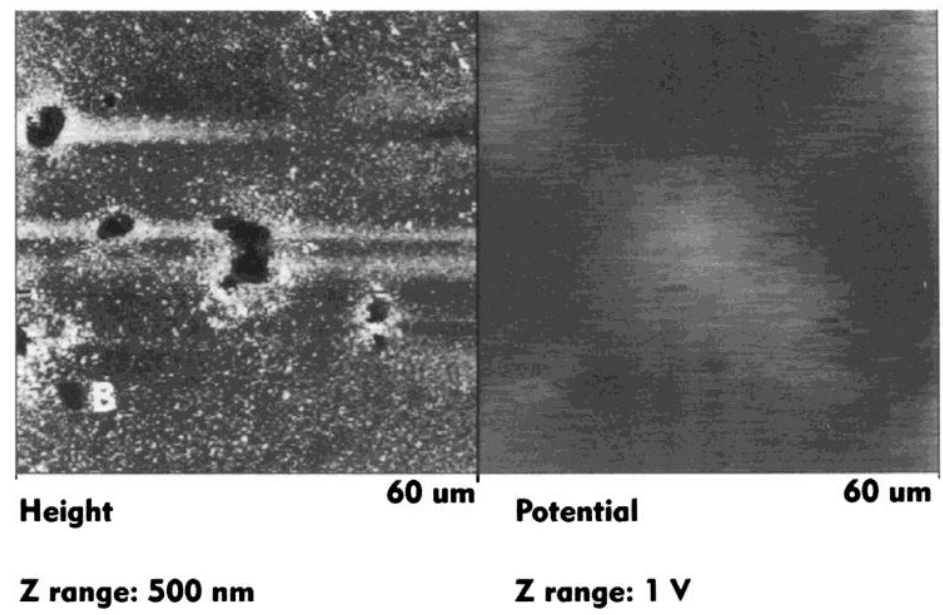

Fig. 5. Topography and Volta potential of the same area as Fig. 1 after 120 min of total exposure in $0.1 \mathrm{M} \mathrm{NaCl}$.

The large particle 2 in the center of Fig. 7 was also an Fe-Mn-rich particle. In contrast to particle 1 in Fig. 7, it was quite stable during the exposure. Particle A in Fig. 7 was not analyzed with EDS, but it dissolved completely during the 30 min exposure, and may have been a Mg-rich intermetallic particle.

To further investigate corrosion of the $\mathrm{Al}-\mathrm{Cu}-(\mathrm{Fe}, \mathrm{Mn})$ particles, a sample was exposed to a more aggressive $0.5 \mathrm{M} \mathrm{NaCl}$ solution for $10 \mathrm{~min}$ and analyzed ex situ, Fig. 10. Two different types of corrosion sites are observed. There is attack at the border of the particle as observed in other studies, ${ }^{7,9}$ but there are also pits within the particle. Despite the more noble initial potential of the intermetallic particle relative to the matrix, it is very reactive and supports both anodic and cathodic reactions. The very bright areas in the topographic map reflect very high regions that may be corrosion products that precipitate at cathodic sites and remain on the surface even 
though the sample was rinsed with deionized water after exposure. The Volta potential in the region of the pits within the particle is noble relative to the rest of the particle, and the high spots on the particle exhibit relatively active potentials. Pits in the matrix were shown above to have a higher Volta potential in air than the rest of the matrix. The same behavior is seen in the trench at the perimeter of the particle as described presently.

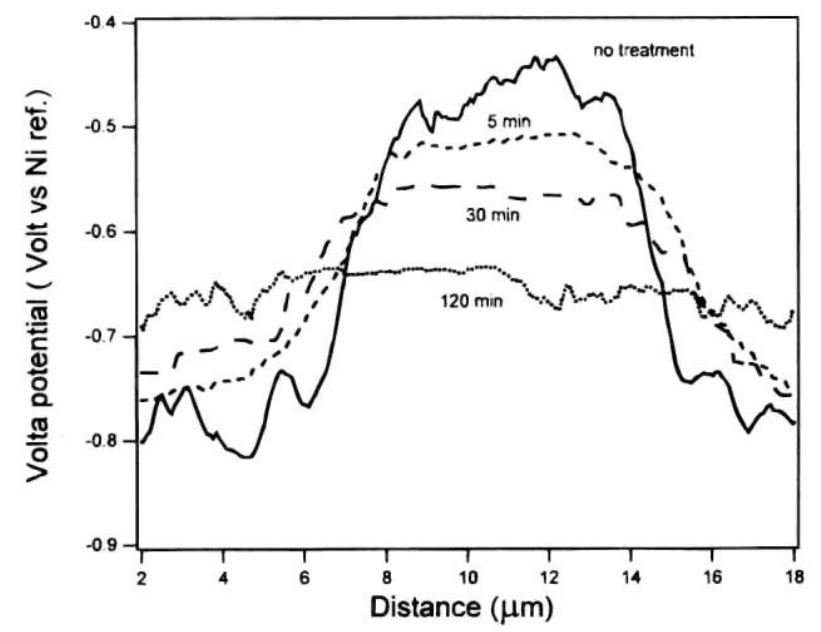

Fig. 6. Volta potential profile across particle 1 of Fig. 1 after different exposure times in $0.1 \mathrm{NaCl}$.

There is considerable dissolution around the edge of the particle as seen by the deep trench in the topographical image of Fig. 10. The enlargement shown in Fig. 11 indicates that directly next to the trench at the very edge of the particle is a ridge that is higher than the rest of the particle. The Volta potential map shows that the potential in the trench is quite high, while that of ridge is uniformly low. The high potential of the trench may also result from enrichment of $\mathrm{Cu}$ as suggested above for pits, which also exhibit high potentials. Clusters approximately 0.1 $\mu \mathrm{m}$ in diameter are seen within the particle and outside of the trench in both the topographic and Volta potential maps. The source of these clusters is not yet clear.

The Volta potential maps determined by the scanning Kelvin probe force microscope technique have been shown above to provide interesting information regarding the pitting behavior of AA2024-T3. It should be noted, however, that the usefulness of this information is limited by several factors. A correlation between the Volta potential measured in air and the open-circuit potential measured in solution has been presented, indicating that this technique provides a measure of the practical nobility of the surface. ${ }^{16}$ However, it is possible that in certain situations, such as for metals that might passivate in air, the potentials measured ex situ might not accurately reflect the condition of the sample in solution. Furthermore, the predictive capabilities of the technique are limited. For instance, changes in the local environment that might not be seen in the potential map can have a dominating influence on the exact location of localized attack. 


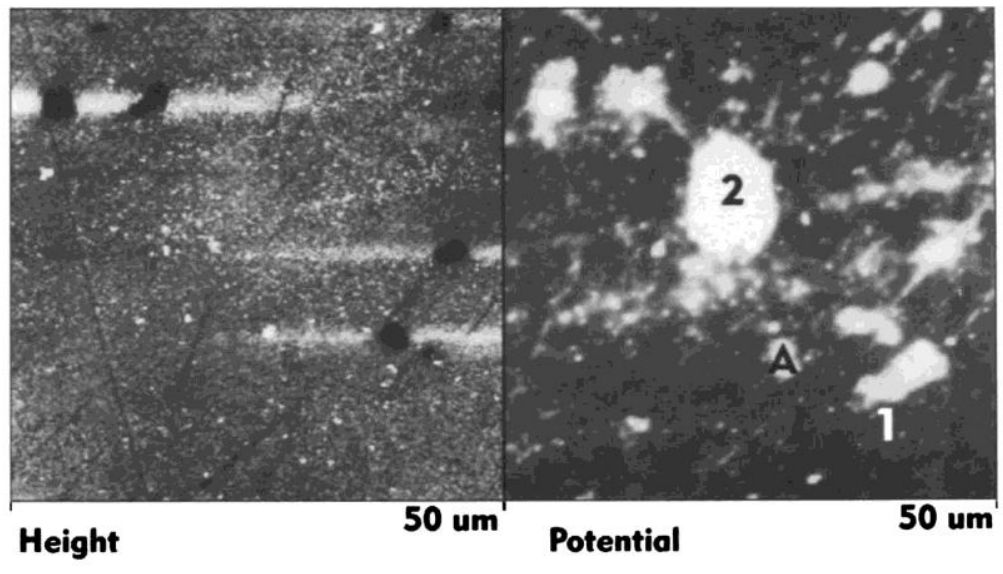

$Z$ range: $300 \mathrm{~nm}$

$Z$ range: $1 \mathrm{~V}$

Fig. 7. Topography and Volta potential of an AA2024-T3 sample before treatment.

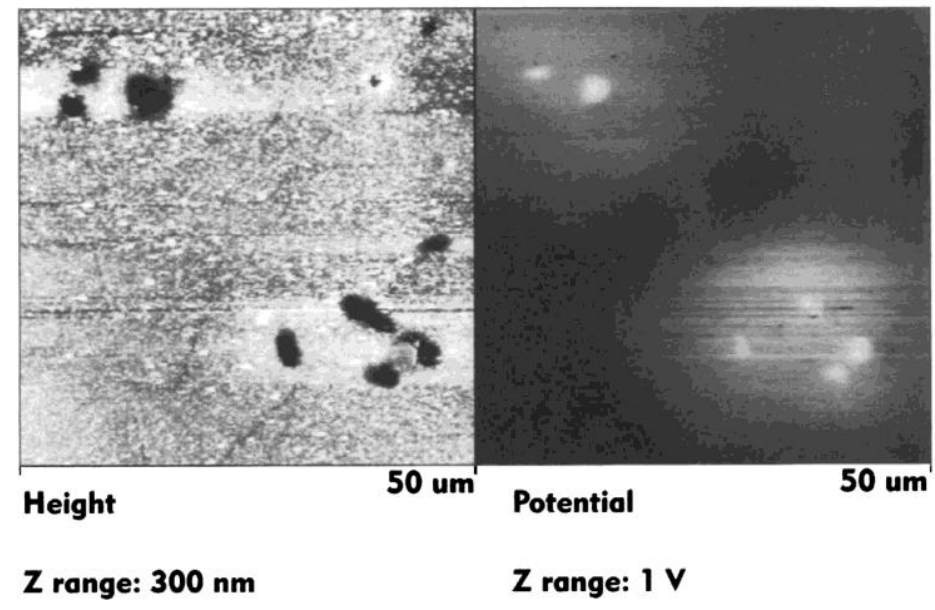

Fig. 8. Topography and Volta potential of the same area as Fig. 7 after $30 \mathrm{~min}$ of $0.1 \mathrm{M} \mathrm{NaCl}$ solution exposure. Two large holes (pits) formed inside particle 1.

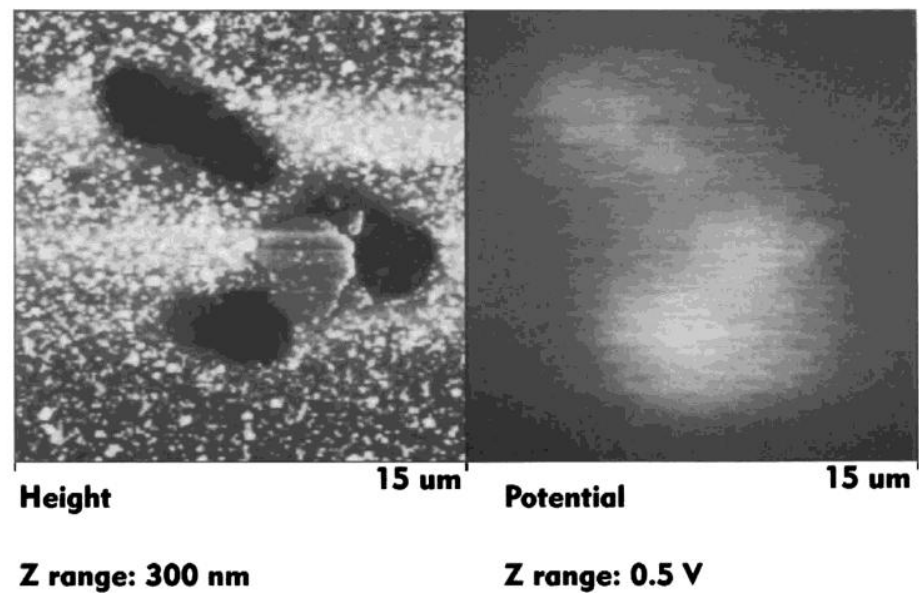

Fig. 9. Enlargement of Fig. 8. 


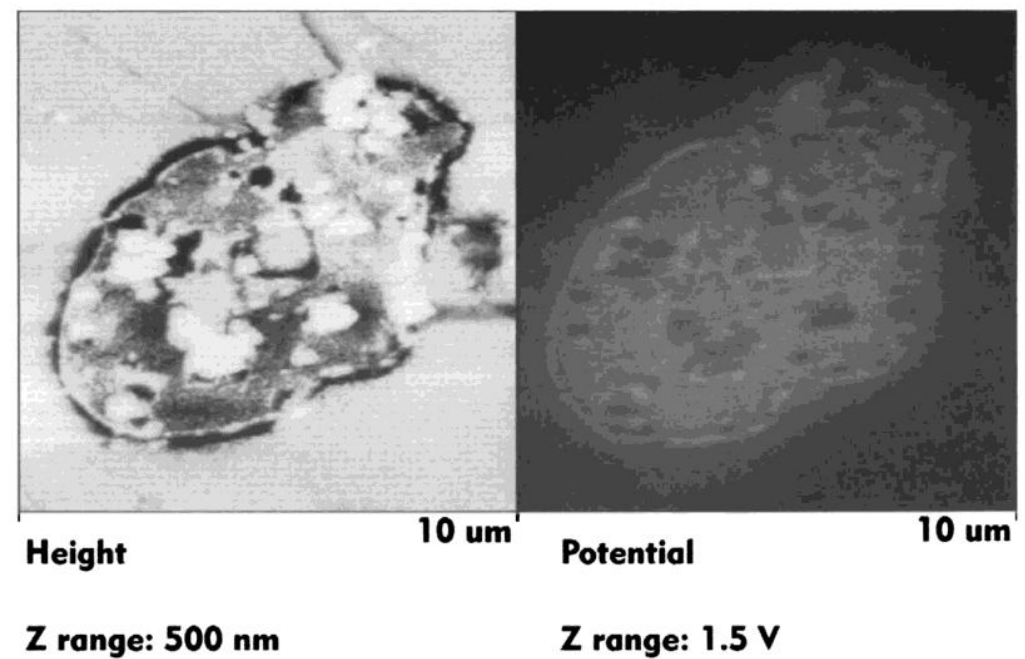

Fig. 10. Topography and Volta potential of an $\mathrm{Al}-\mathrm{Cu}-(\mathrm{Fe}, \mathrm{Mn})$ intermetallic particle following exposure to $0.5 \mathrm{M}$ $\mathrm{NaCl}$ for $10 \mathrm{~min}$.

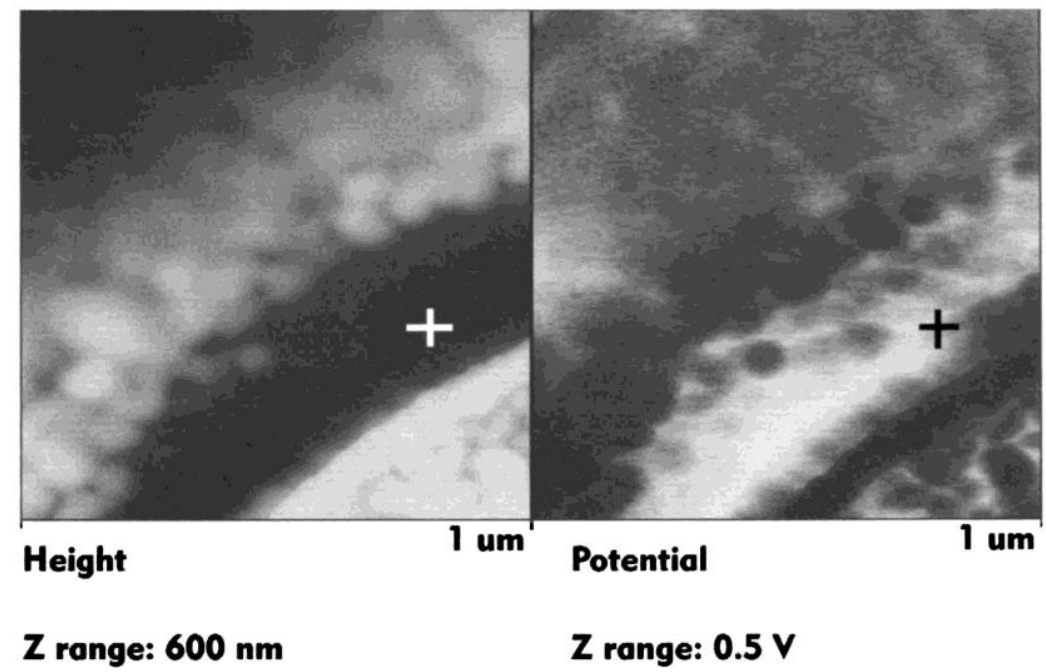

Fig. 11. Enlargement of Fig. 10 showing the trench formed around the particle. The marker indicates the bottom of the trench, which has a high potential.

AFM scratching in solution.-The effect of AFM imaging of the surface in solution in contact mode was first investigated with commercially pure Al (AA1100) in $0.5 \mathrm{M} \mathrm{NaCl}$. Figure 12 is an in situ image of a region of the sample, the center of which had been rastered for $30 \mathrm{~min}$ at a high contact force with a Si tip. The accelerated dissolution of $\mathrm{Al}$ as a result of contact mode rastering of the AFM tip is similar to that reported by Chen and Guay. ${ }^{13,14}$ The effect of the set point voltage at the photodiode (which is related to the force on the tip through the spring constant of the cantilever) on the rate of dissolution is shown in Fig. 13. At the lowest possible set point voltage of $0.2 \mathrm{~V}$, which corresponds to a force between 150 and $350 \mathrm{nN}$, no accelerated dissolution of the rastered area relative to the neighboring region could be detected. It should be noted that the depth resolution of this measurement is about $2 \mathrm{~nm}$. Therefore, in order to detect accelerated dissolution in the rastered area relative to the matrix during a $30 \mathrm{~min}$ treatment, the 
rate of dissolution in the rastered area needed to be larger than $0.07 \mathrm{~nm} / \mathrm{min}$. The error bars in Fig. 13 reflect this uncertainty.

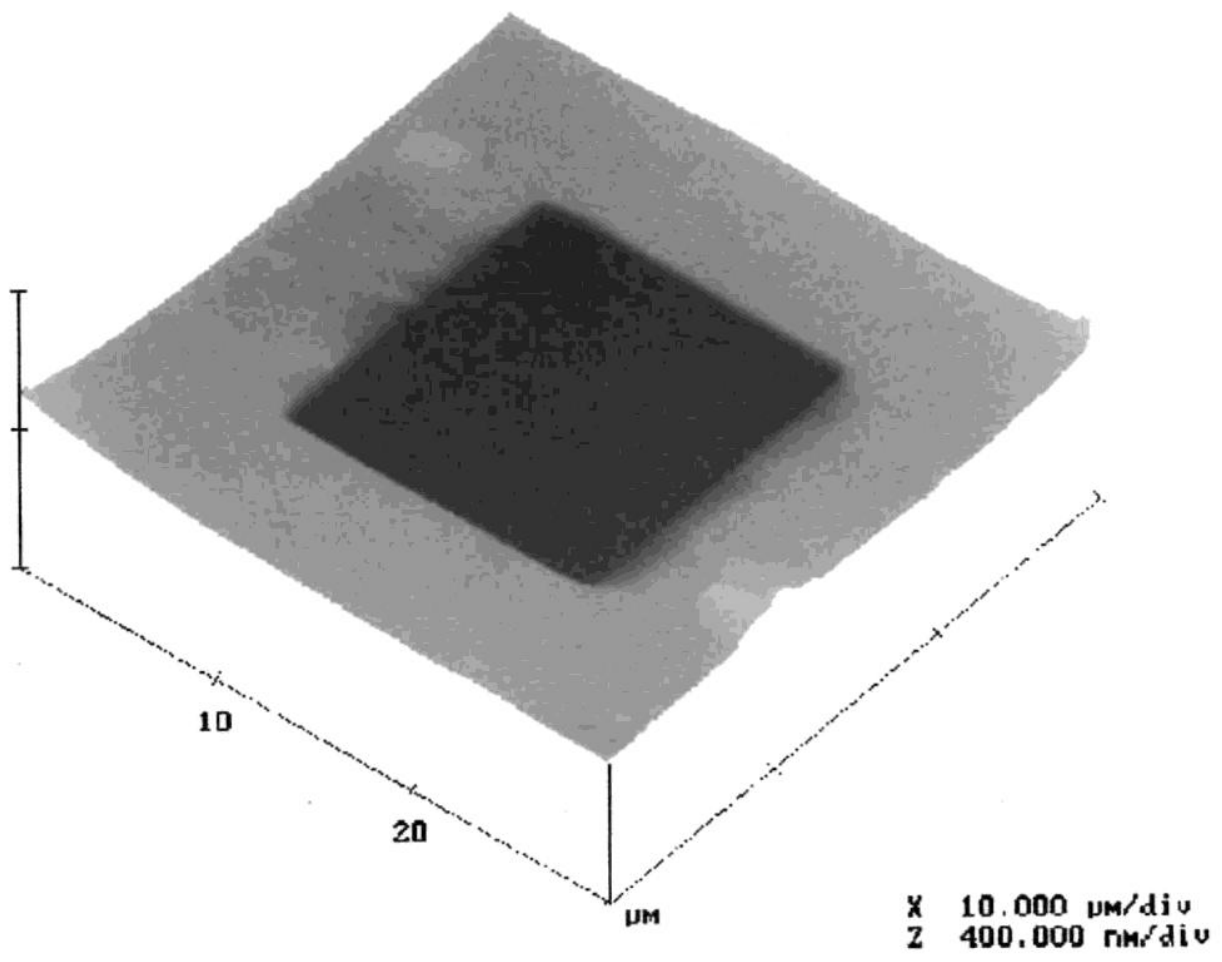

Fig. 12. In situ topographic map of a $15 \mu \mathrm{m}$ square hole in AA1100 obtained by contact mode rastering of the AFM tip in $0.5 \mathrm{M} \mathrm{NaCl}$.

As the set point voltage was increased above $0.2 \mathrm{~V}$, the rate of dissolution of the rastered area increased. A plateau of $0.16 \mathrm{~nm} / \mathrm{min}$ at a set point of $2 \mathrm{~V}$ was followed by a further increase in the dissolution rate, and finally by another plateau of $0.43 \mathrm{~nm} / \mathrm{min}$ after about $4 \mathrm{~V}$. The increase after the first plateau may be caused by the AFM tip breaking through the passive film. A dissolution rate of $0.4 \mathrm{~nm} / \mathrm{min}$ is equivalent to an average anodic current density of approximately $2 \times 10^{-5} \mathrm{~A} / \mathrm{cm}^{2}$. Assuming that the nominal passive current density for pure $\mathrm{Al}$ at this potential in $0.5 \mathrm{M} \mathrm{NaCl}$ is $1 \times 10^{-6} \mathrm{~A} / \mathrm{cm}^{2},{ }^{21}$ the average rate during rastering is increased by a factor of 20 . However, the tip passes a given spot only once during each scan of the $15 \times 15$ $\mu \mathrm{m}$ area, which takes $4.3 \mathrm{~min}$ to complete. If the contact area is equal to the hemispherical area of a $50 \mathrm{~nm}$ radius tip (or $1.6 \times 10^{-2} \mu \mathrm{m}^{2}$ ), each spot on the surface is in contact with the tip only $0.007 \%$ of the time during rastering, corresponding to $18 \mathrm{~ms}$. If the metal dissolution is assumed to occur only during the period when the tip is in contact with any given spot, the dissolution rate during rastering is actually about $0.3 \mathrm{~A} / \mathrm{cm}^{2}$. Current transients measured following the creation of a fresh $\mathrm{Al}$ surface by the breaking of a thin film in sulfate solution have indicated that the current densities are on the order of $1000 \mathrm{~A} / \mathrm{cm}^{2}$ during the first few microseconds, but decay to the range of $0.1-1 \mathrm{~A} / \mathrm{cm}^{2}$ after $1 \mathrm{~ms}^{11}$ 


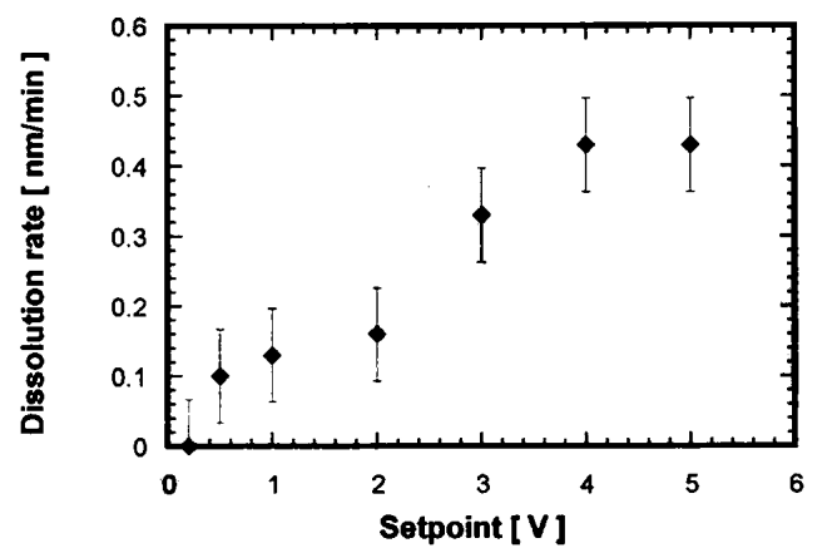

Fig. 13. Dissolution rate as a function of set point voltage on photodiode (proportional to force applied on the surface) obtained on AA1100 in $0.5 \mathrm{M} \mathrm{NaCl}$.

The dissolution rate during rastering of the AFM tip in solution is therefore similar to what would be expected by repassivation measurements during the same time period. It is interesting to note that scratching of the pure $\mathrm{Al}$ sample in $0.5 \mathrm{M} \mathrm{NaCl}$ did not generate stable dissolution in the form of pits even though $\mathrm{Al}$ might not be expected to repassivate spontaneously in this solution.

Influences of galvanic interaction between the $\mathrm{Si}$ tip and exposed $\mathrm{Al}$ area during scratching cannot be excluded. Given the relative nobility of Si and $\mathrm{Al}$, it is expected that, were such galvanic interaction occurring, the potential of the Al would be increased. The relationship of dissolution rate to tip force shown in Fig. 13 is specific to the combination of pure $\mathrm{Al}$ in $0.5 \mathrm{M}$ $\mathrm{NaCl}$. Some other combinations of material and environment have been investigated. For instance, rastering in distilled water does not result in accelerated dissolution of aluminum, which has also been reported by Chen and Guay. ${ }^{13}$

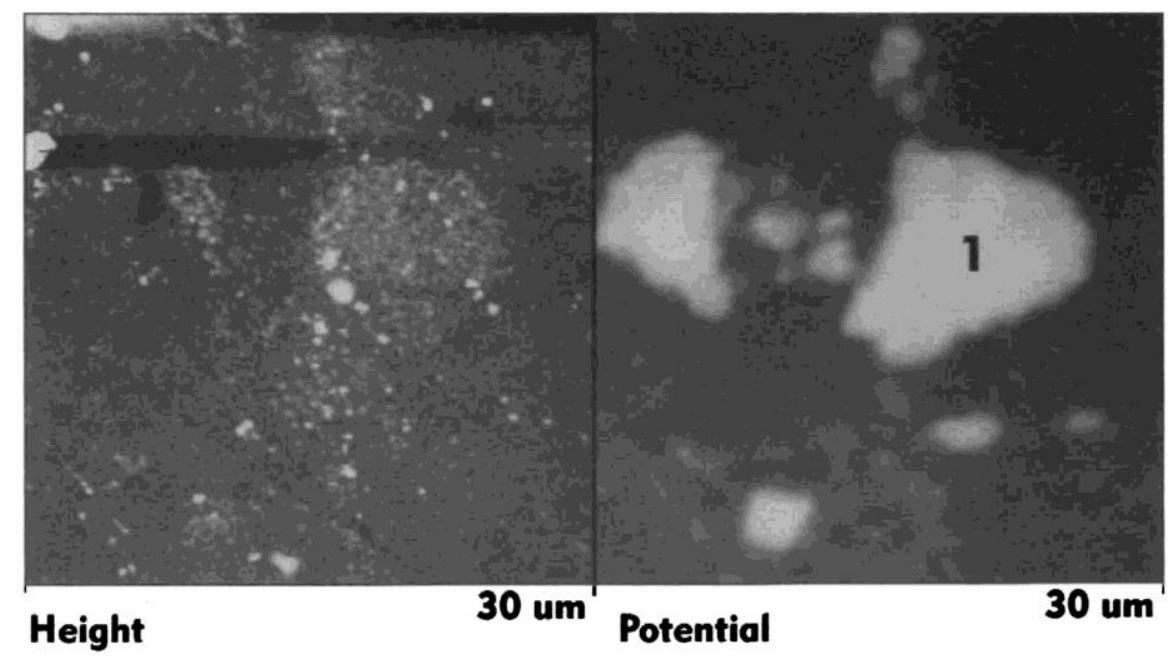

\section{$Z$ range: $200 \mathrm{~nm}$}

$Z$ range: $1 \mathrm{~V}$

Fig. 14. Topography and Volta potential of an AA 2024-T3 sample before treatment. The particle is an AI-Cu-(Fe, $\mathrm{Mn})$ intermetallic. 
The effect of AFM rastering in situ was studied for AA2024-T3 in 0.01 M NaCl. The Al$\mathrm{Cu}-(\mathrm{Fe}, \mathrm{Mn})$ intermetallic particles were shown above to exhibit heterogeneities and to dissolve nonuniformly in a more concentrated chloride solution. Figure 14 shows a uniform potential distribution on the Fe-Mn containing particle 1 before solution exposure. This region was then rastered continuously in contact mode at the lowest set point voltage of $0.2 \mathrm{~V}$ in $0.01 \mathrm{M} \mathrm{NaCl}$ solution. After $12 \mathrm{~h}$ of rastering, a topographic contrast between the particle and the matrix is obtained because of enhanced dissolution of the aluminum matrix relative to the particle even at this low force, Fig. 15. The difference in height between the inter-metallic particle and the matrix is around $20 \mathrm{~nm}$, which gives a minimum dissolution rate for the aluminum matrix of 0.03 $\mathrm{nm} / \mathrm{min}$, assuming that the intermetallic particle does not dissolve at all. However, the Volta potential contrast within the particle in Fig. 15 suggests that at least a surface layer has been removed. Recall that no discernible dissolution of pure Al was found after $30 \mathrm{~min}$ at this setpoint voltage in $0.5 \mathrm{M} \mathrm{NaCl}$, but the resolution of that measurement was only $0.07 \mathrm{~nm} / \mathrm{min}$.

The Volta potential map in Fig. 15 shows that the border of the particle is more noble than the interior. A similar distribution in Volta potential was seen for Al-Cu-(FeMn) particles after sputter etching, and backscattered electron images have shown that heavy elements are often concentrated at the edges of these particles. ${ }^{16}$ The dissolution occurring as a result of the tip abrasion resulted in a similar etching of the surface oxide to reveal the heterogeneities in the particle.

$\mathrm{Al}-\mathrm{Cu}-\mathrm{Mg}$ intermetallic particles respond quite differently to in situ contact rastering. Figure 16 shows a selected region before immersion. Particles 1 and 2 are $\mathrm{Al}-\mathrm{Cu}-(\mathrm{Fe}, \mathrm{Mn})$ intermetallics, whereas particles $\mathrm{A}$ and $\mathrm{B}$ are $\mathrm{Al}-\mathrm{Cu}-\mathrm{Mg}$ intermetallics. This sample was then immersed in $0.01 \mathrm{M} \mathrm{NaCl}$ and imaged in contact mode at the lowest set point voltage of $0.2 \mathrm{~V}$. Figure 17 is the first topographic map of the area made in situ. The topography is identical to that in air prior to immersion (left side of Fig. 16). The second in situ scan, initiated approximately $4.3 \mathrm{~min}$ after the first, is shown in Fig. 18. The two Al-Cu-Mg particles in the center of the image are already completely dissolved by the time that the tip returns to that location. Holes a few hundred nanometers deep are visible at the locations where the Al-Cu-Mg particles had been. An interesting observation in Fig. 18 is that only the particle B corrodes homogeneously. The lower part of particle $\mathrm{A}$ is completely dissolved, but the top part exhibits ditching around the perimeter. After 60 min of rastering in solution, the topography is dominated by a ring of corrosion products, Fig. 19. The depth of the pits does not change with time after the initial dissolution shown in Fig. 18.

The light scratching of the surface by the AFM tip obviously has a tremendous influence on the stability of the Al-Cu-Mg particles. As described above, more than $30 \mathrm{~min}$ of simple immersion in the more concentrated $0.1 \mathrm{M} \mathrm{NaCl}$ solution were required for a particular $\mathrm{Al}-\mathrm{Cu}-$ $\mathrm{Mg}$ particle to be activated and dissolve. This initiation time was related to the limited stability of a surface layer which had to be removed. The tip-surface interaction during in situ contact mode AFM imaging obviously enhances the destabilization of this layer. The stiffness of the silicon cantilever used in this work is higher than that of silicon nitride cantilevers used commonly for contact mode imaging. This was done purposely to enhance the applied force at the tip. However, AFM imaging in contact mode of a corroding sample in solution should be performed with care if this type of accelerated dissolution is to be avoided.

The Al-Cu-Mg particles are in most cases completely dissolved after a certain initiation time. It can therefore be assumed that the structure of these particles is homogeneous or at least 
that composition gradients do not have a significant effect on the dissolution process.

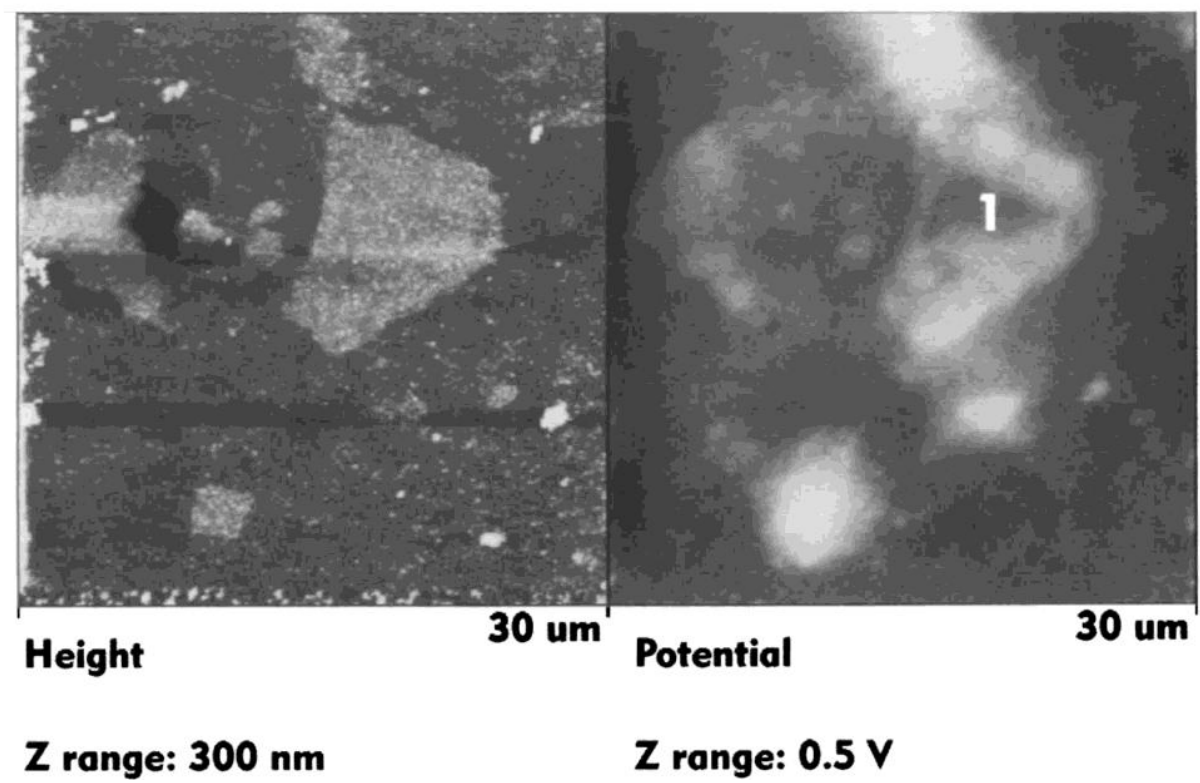

Fig. 15. Topography and Volta potential of the same region as Fig. 14 after rastering with the AFM tip in $0.01 \mathrm{M}$ $\mathrm{NaCl}$ for $12 \mathrm{~h}$ at low force.

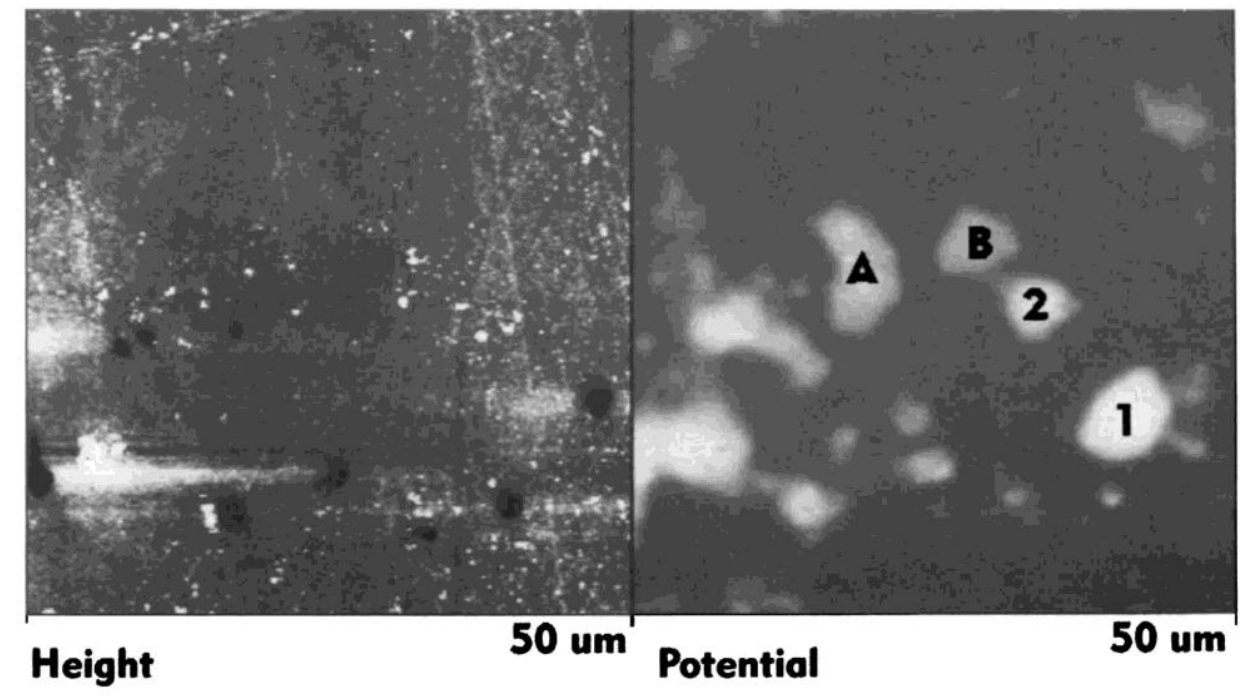

\section{$Z$ range: $200 \mathrm{~nm} \quad Z$ range: $1.5 \mathrm{~V}$}

Fig. 16. Topography and Volta potential of an AA2024-T3 sample before treatment. Particles A and B are Al-Cu$\mathrm{Mg}$ intermetallics, and particles 1 and 2 are $\mathrm{Al}-\mathrm{Cu}-(\mathrm{Fe}, \mathrm{Mn})$ intermetallics. 


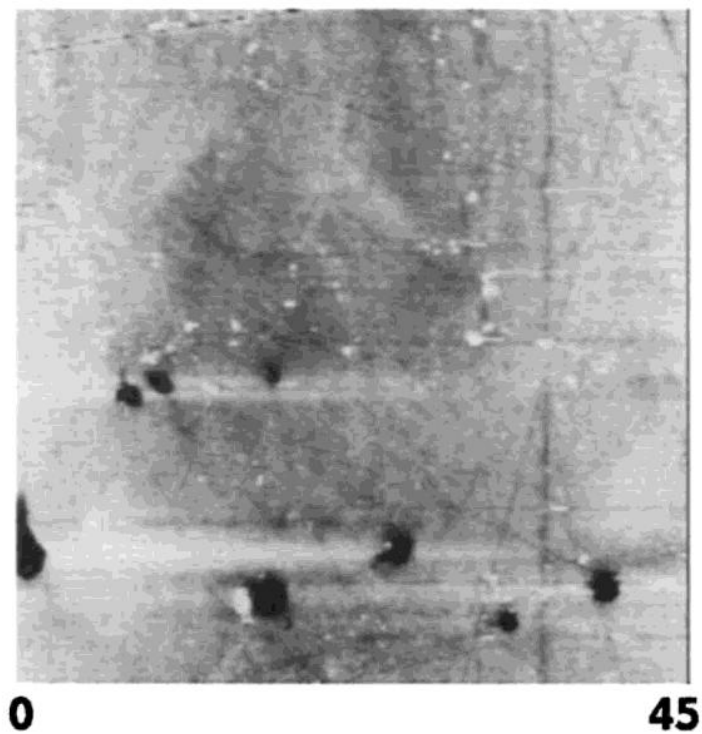

um

\section{$Z$ range: $200 \mathrm{~nm}$}

Fig. 17. In situ topographic map of the same area as Fig. 16. First scan during $0.01 \mathrm{M} \mathrm{NaCl}$ exposure.

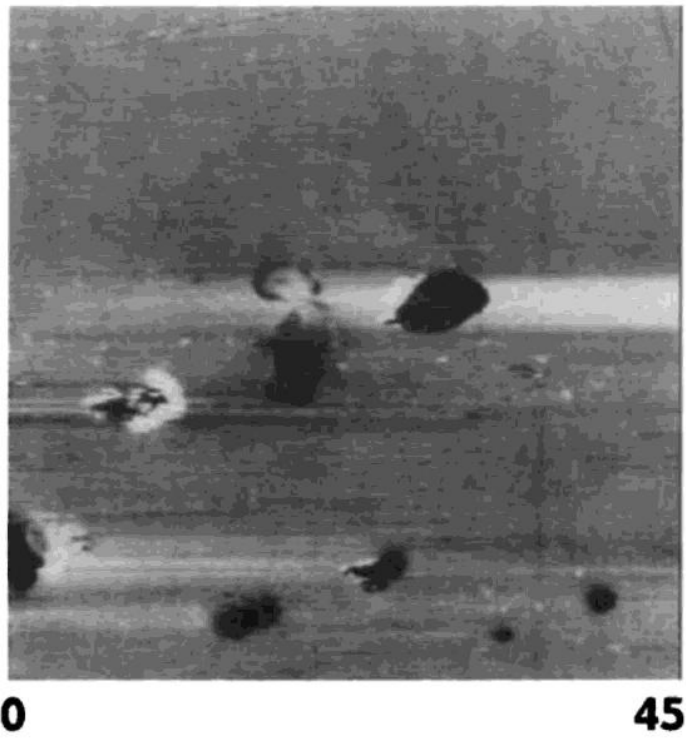

um

\section{$Z$ range: 1 um}

Fig. 18. In situ topographic map of the same area as Fig. 16. Second scan in $0.01 \mathrm{M} \mathrm{NaCl}$. 

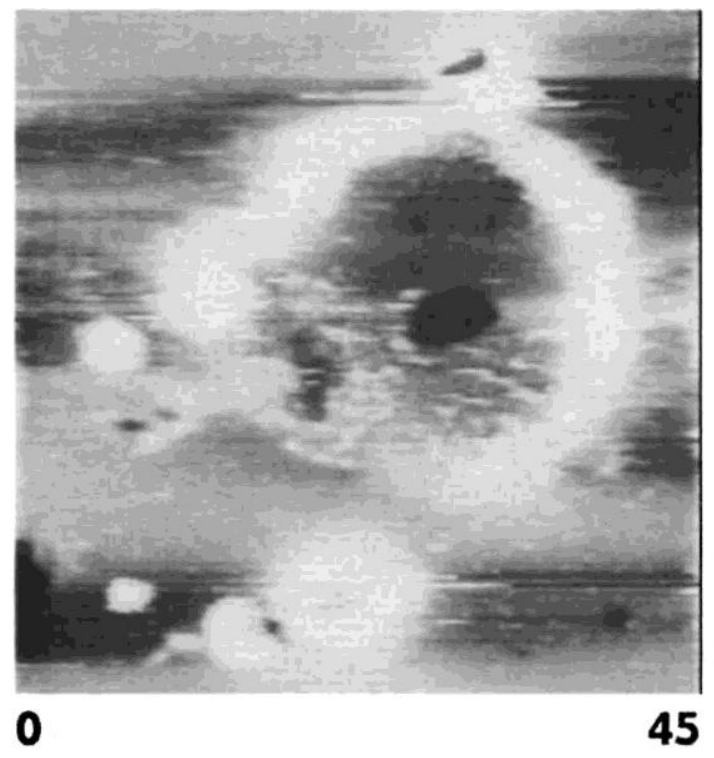

um

\section{$Z$ range: 3 um}

Fig. 19. In situ topographic map of the same area as Fig. 16 after $1 \mathrm{~h}$ of exposure in $0.01 \mathrm{M} \mathrm{NaCl}$ solution.

\section{Conclusions}

The atomic force microscope was used to study the corrosion of AA2024-T3 by providing topographic and Volta potential maps, and by accelerating dissolution via local in situ scratching of the surface. The following observations were made.

1. The dissolution rate of pure $\mathrm{Al}$ in $0.5 \mathrm{M} \mathrm{NaCl}$ was found to be accelerated by rastering of the AFM tip across the surface if the tip force was above a certain minimum value.

2. Al-Cu-Mg intermetallic particles are protected by a noble surface layer that delayed the corrosion of these otherwise active particles. The noble potential measured on these particles decreases with immersion time. When the particle becomes active relative to the matrix, it rapidly dissolves away.

3. Light scratching of the surface by rastering with the AFM tip in contact mode at the lowest set point voltage in dilute $0.01 \mathrm{M} \mathrm{NaCl}$ resulted in immediate dissolution of the $\mathrm{Al}-\mathrm{Cu}$ $\mathrm{Mg}$ particles. This abrasion by the tip enhances the destabilization of the surface film on the particles.

4. Inhomogeneities in the $\mathrm{Al}-\mathrm{Cu}-(\mathrm{Fe}, \mathrm{Mn})$ intermetallic particles and a generally increased surface reactivity relative to the matrix resulted in nonuniform dissolution of the particles in more concentrated chloride solutions despite the noble Volta potential.

5. Trenches with more noble Volta potential formed around the particles, and elevated regions with low potential associated with corrosion products were present on the particles.

6. Light scratching of a region that included an $\mathrm{Al}-\mathrm{Cu}-(\mathrm{Fe}, \mathrm{Mn})$ intermetallic particle by rastering with the AFM tip in contact mode at the lowest set point voltage in dilute $0.01 \mathrm{M} \mathrm{NaCI}$ resulted in etching of the particle and preferential dissolution of the neighboring matrix phase. 


\section{Acknowledgments}

This work was supported by the Air Force Office of Scientific Research under contact no. F49620-96-10479, Major H. De Long, Administrator. P. S. was partially supported by the Swiss National Foundation of Research. M. Kendig, S. L. Jeanjacquet, and W. Schmidt are gratefully acknowledged for providing samples and for interesting discussions.

The Ohio State University assisted in meeting the publication costs of this article.

\section{REFERENCES}

1. C. Blanc, B. Lavelle, and G. Mankowski, Corros. Sci., 39,495(1997).

2. A. Conde and J. D. Damborenca, Corros. Sci., 39, 295 (1997).

3. F. Mansfeld and Y. Wang, Br. Corros. J., 29, 194 (1994).

4. H. Shih and F Mansfeld, Corrosion, 45, 610 (1989).

5. R. G. Buchheit, J. Electrochem. Soc., 142, 610 (1989).

6. R. G. Buchheit, R. P. Grant, P. F. Hlava, B. McKenzie, and G. L. Zender, J. Electrochem. Soc., 144, 2621 (1997).

7. R. M. Rynders, C. H. Paik, R. Ke, and R. Alkire, J. Electrochem. Soc., 141, 1439 (1994).

8. T. J. Warner, M. P. Schmidt, F. Sommer, and D. Bellot, Z. Metallkd., 86, 494 (1995).

9. K. Kowal, J. DeLuccia, J. Y. Josefowicz, C. Lair, and G. C. Farrington, J. Electrochem. Soc., 143, 2471 (1996).

10. G. T. Burstein and G. Gao, J. Electrochem. Soc., 138, 2627(1991).

11. G. S. Frankel, C. V. Jahnes, V. Brusic, and A. J. Davenport, J. Electrochem. Soc., 142, 2290 (1995).

12. G. T. Burstein and R. J. Cinderey, Corros. Sci., 32, 1195 (1991).

13. L. Chen and D. Guay, J. Electrochem. Soc., 141, L43 (1994).

14. L. Roue, L. Chen, and D. Guay, Langmuir, 12, 5818(1996).

15. Y. Zhu and D. E. Williams, J. Electrochem. Soc., 144, L43 (1997).

16. P. Schmutz and G. Frankel, J. Electrochem. Soc., 145, 2285 (1998).

17. A. C. Hillier, S. Kim, and A. J. Bard, J. Phys. Chem., 100, 18808 (1996).

18. H. J. Butt, Nanotechnology, 3, 60 (1992).

19. T. J. Senden, C. J. Drummond, and P. Kekicheff, Langmuir, 10, 358 (1994).

20. B. Mazurkiewicz, Corros. Sci., 23, 687 (1983).

21. E. McCafferty, Corros. Sci., 37, 481 (1995). 